\title{
LIQUIDITY DEFLATION AND LIQUIDITY TRAP UNDER FLEXIBLE PRICES: SOME MICROFOUNDATIONS AND IMPLICATIONS
}

\author{
Guillermo A. Calvo \\ Working Paper 26277 \\ http://www.nber.org/papers/w26277 \\ NATIONAL BUREAU OF ECONOMIC RESEARCH \\ 1050 Massachusetts Avenue \\ Cambridge, MA 02138 \\ September 2019
}

I am thankful to Ricardo Caballero, Sara Calvo and Martín Uribe for useful comments on a previous version. Errors and omissions are exclusively mine. The views expressed herein are those of the author and do not necessarily reflect the views of the National Bureau of Economic Research.

NBER working papers are circulated for discussion and comment purposes. They have not been peer-reviewed or been subject to the review by the NBER Board of Directors that accompanies official NBER publications.

(C) 2019 by Guillermo A. Calvo. All rights reserved. Short sections of text, not to exceed two paragraphs, may be quoted without explicit permission provided that full credit, including ( $)$ notice, is given to the source. 
Liquidity Deflation and Liquidity Trap under Flexible Prices: Some Microfoundations and Implications

Guillermo A. Calvo

NBER Working Paper No. 26277

September 2019

JEL No. E31,E4,E41,E5,E52

\begin{abstract}
The paper discusses simple microfoundations for Liquidity Deflation (Calvo 2016, Chapter 2), which gives rise to liquidity trap under perfectly flexible prices/wages. Unlike Keynes (1936), this is a Supply Side Liquidity Trap, SSLT, not resolved by a fall in prices /wages, or massive helicopter increase in liquid government liabilities. However, escaping SSLT could be achieved by low policy interest rates on money (unless ZLB holds) and, more interestingly, higher inflation driven by administered prices/wages. Moreover, contrary to (Friedman 1969), under Liquidity Deflation the Optimal Quantity of Money does not call for liquidity satiation, and may be dangerously close to SSLT.
\end{abstract}

Guillermo A. Calvo

Columbia University

School of International and Public Affairs

420 West 118th St, Room 1303B

MC3332

New York, NY 10027

and NBER

gc2286@ columbia.edu 


\title{
LIQUIDITY DEFLATION AND LIQUIDITY TRAP UNDER FLEXIBLE PRICES Some Microfoundations and Implications
}

\author{
Guillermo Calvo \\ September 3, 2019
}

\section{INTRODUCTION}

Several recent papers suggest that shortage of very liquid (also called safe) assets could be a central explanatory factor for the deep and long-lasting Great Recession that followed the Lehman crisis. This is traced back to the massive destruction of safe assets associated with the Lehman crisis (see Calvo 2012, Caballero, Farhi and Gourinchas 2016 and 2017), which gave rise to large demand for and insufficient creation of safe assets due to constraints like the Zero Lower Bound on policy interest rates, ZLB, and sterilized intervention. The ZLB is hard to bypass because it involves thorny operational problems but, in principle, unsterilized intervention, like helicopter money, should be less problematic. Therefore, part of the difficulty could be attributed to governments' reluctance to utilize unsterilized intervention. But the effectiveness of helicopter money is not free from critics. Keynes (1936), for instance, raised some doubts about the effectiveness of unsterilized intervention by conjecturing that there exists a positive nominal interest rate at which the demand for money becomes infinitely elastic - a situation labeled Liquidity Trap. However, Keynes's conjecture is hard to justify in conventional models since, given the price level, helicopter money could increase real wealth without bound and, if there is no consumption satiation, utility maximization should eventually lead to a rise in aggregate demand that matches full capacity output (as implied by the Pigou effect). This criticism to Keynes's conjecture, though, is due to an assumption that is taken for granted in conventional macro models, namely, that the liquidity services provided by money are proportional to the stock of real monetary balances. This assumption sounds reasonable in normal circumstances, away from Liquidity-Trap type episodes, but it may be questionable when, as in the Great Recession, the velocity of circulation of monetary aggregates (e.g., M1 and M2) in the US, has fallen to levels not seen in more than half a century. ${ }^{1}$

In recent work I have explored the possibility of a disconnect between real safe assets (i.e., the nominal supply of safe assets divided by the price level), and their liquidity or transaction services - and argued that beyond a certain point an increase in real safe assets may fail to increase total liquidity in the same proportion. I labeled this phenomenon Liquidity Deflation. As shown in Calvo (2016 $\mathrm{a}$ and $\mathrm{b}$ ) and discussed below, Liquidity Deflation helps to validate Keynes's

\footnotetext{
${ }^{1}$ In this paper I will indistinguishably speak of safe, highly liquid assets and money. The focus is on assets that are essential for trade and financial transactions, including assets that are employed for credit collateral. Their composition is not central for the present discussion, and will be largely ignored.
} 
conjecture even though expansion of monetary aggregates is triggered by helicopter money, and the interest elasticity of the demand for money is bounded.

The ideas behind Liquidity Deflation are straightforward, but I have encountered some intellectual resistance in considering its relevance. Part of the reason for this is that in macroeconomics the concept of "money" is associated with an object which liquidity is tarnished by nothing except "inflation". In particular, increasing the supply of "reserve assets," (i.e., assets employed by central banks as international reserves, like US Treasury obligations) is rarely associated in models with a loss of their "liquidity" or transaction services. Thus, I believe that time is high for discussing the microfoundations of Liquidity Deflation and, on that basis, get new insights on macro policy around Liquidity Trap episodes. These are the central issues tackled in the present paper.

To motivate the discussion, I will first briefly present in plain English two related Liquidity Deflation scenarios. Then I will spell out a formal model, which will allow us to discuss the mechanics of Liquidity Deflation in greater detail and show, under conventional assumptions, that Liquidity Deflation could completely crowd out the liquidity-enhancing impact of an increase in money supply. Moreover, the model shows that operating near the complete-crowd-out equilibrium is also problematic. Under those conditions, even a slow-paced return to normality may bring about a sharp and unwelcome increase in the price level.

As a bonus, and to insert Liquidity Deflation at the core of conventional monetary theory, I examine the Optimal Quantity of Money, OQM, issue originally discussed in Friedman (1969, Chapter 1). I show that, unlike Friedman's OQM, Liquidity Deflation does not call for reaching liquidity satiation and that the new OQM is located dangerously close to the new Liquidity Trap concept developed in this paper.

In the closing remarks I present a short and tentative extension of these ideas to Emerging Market economies, EMs, in which domestic assets could hardly be classified as safe. Arguably, however, the search for yield triggered by low-interestrate of safe assets may have turned some EM assets safer (perhaps due to higher turnover), helping to explain the noticeable recent downward trend in EM inflation (see Ha et al 2019). 


\section{LIQUIDITY DEFLATION}

\section{a. Intuitive Scenarios}

1) Consider an atomistic representative-individual economy in which carrying cash to the mall saves shopping time (see Végh 1989). However, time saved declines as cash held by the other mall customers goes up: a congestion effect. Therefore, from the point of view of each atomistic agent, in equilibrium the time-saving impact of cash holdings increases less than in proportion to cash held-a phenomenon I label Liquidity Deflation.

2) Alternatively, and more in line with popular narratives of the Great Recession (see Gorton 2010), consider the case in which a highly liquid asset (e.g., US Treasury bond) is used as credit collateral. The collateral value of those bonds depends on the amount of goods and services that the US government could seize by, say, raising emergency taxes. Therefore, if the latter has an upper bound, in equilibrium the value of Treasury bonds as collateral may increase less than in proportion to the increase in the (real) market value of Treasury bonds: another example of Liquidity Deflation.

Remark I. The above examples assume that liquid government liabilities are safe. However, this assumption is highly debatable for economies, like Japan and the US, that exhibit large fiscal deficits and debt-to-GDP ratios (especially, if unfunded social security benefits are taken into account). Keynes (1936) offers an alternative explanation, which I labeled the Price Theory of Money, PTM, in Calvo (2016 b). ${ }^{2}$ The conjecture is based on the observation that sticky prices provide an unintended output backing to money, even if the public sector offers none. Keynes's rationalization is independent of government's money backing, and its appeal is thus enhanced under current conditions in which, otherwise, currencies like the US dollar and the yen would have to be backed by fiscally fragile governments. Notice that under the PTM, if real monetary balances are 'small' relative to the value of transactions subject to sticky prices, money offers safe liquidity, e.g., free from 'runs.' ${ }^{3}$ However, safety may deteriorate as the stock of real monetary balances becomes large, for the simple reason that, realistically, the flow of real transactions subject to sticky prices has an upper bound.

\footnotetext{
2 To quote the master (emphasis mine): "[...] the fact that contracts are fixed, and wages are usually somewhat stable in terms of money, unquestionably plays a large part in attracting to money so high a liquidity-premium" Keynes 1936, Chapter 17. 3 This helps to explain why currencies that are employed for invoicing and units of account across world economy, like the US dollar, become stronger in terms of output during a Liquidity Crunch episode.
} 


\section{b. Parsimonious Microfounded Flexible Prices Model}

Suppose a standard infinite-horizon, representative-individual open-economy model in which instant utility index satisfies:

$$
u(c)-l \text {, }
$$

where $c$ stands for consumption, $u$ is twice-continuously differentiable over the positive real line, $u^{\prime}>0, u^{\prime \prime}<0$, and $l$ is labor required to consume $c$, e.g., shopping time (see Végh1989). I assume that shopping time increases with consumption and declines with the holdings of real monetary balances. The latter provide transactions services and thus save on shopping time. However, the effectiveness of money to provide those services declines as market holdings of real monetary balances increase, in line with the above examples. In example II.a.1 the effect can be interpreted as "congestion," while in example II.a.2 it can be interpreted as a decline in money's collateral value. ${ }^{4}$

I assume that

$$
l=c-V\left(m+Z\left(m^{e}\right)\right), V^{\prime}>0, V^{\prime \prime}<0, Z^{\prime}<0, Z^{\prime \prime} \leq 0,
$$

where $V$ and $Z$ are, respectively, the timesaving and Liquidity Deflation functions; both are twice-continuously differentiable over the positive real line, and $m$ and $m^{e}$ are, respectively, the representative individual's holding of real monetary balances and market equilibrium real monetary balances (individuals are atomistic and total population is normalized to 1 ). Thus, in equilibrium, $m=m^{e}$. Individuals can single-handedly determine $m$, but, since they are atomistic, are constrained to take $m^{e}$ as given.

For simplicity, I will assume an open economy, rational expectations (= perfect foresight because there is no uncertainty), no trade barriers and perfect capital mobility. The representative individual has a constant endowment, $y$, of (perishable) exportables that are not consumed at home. On the other hand, consumption $c$ is entirely composed of (perishable) importables. The relative international price between importables and exportables is constant and equal to unity. Moreover, the international real interest rate is positive, equals the representative individual's subjective rate of discount, $\rho$, and (importantly for our

\footnotetext{
${ }^{4}$ It is worth noting that, strictly speaking, the Price Theory of Money does not apply if prices are perfectly flexible. However, I assume price flexibility here to show that, granted Liquidity Deflation, price stickiness is not indispensable for existence of Liquidity Trap. Extensions to sticky prices are straightforward, but, at this juncture, would cloud the analysis with superfluous details. For an attempt in that direction, see Calvo (2018).
} 
discussion here) exchange rate and prices are perfectly flexible. Thus, the budget constraint of the representative individual in terms of tradable goods satisfies:

$$
\int_{0}^{\infty}\left[y+s_{t}-c_{t}-i_{t} m_{t}\right] e^{-\rho t} d t \geq 0,
$$

where, without loss of generality, initial wealth is set equal to zero, and $i$ and $s$ stand, respectively, for the market instantaneous nominal interest rate and government's lump-sum subsidies to rebate seigniorage from money creation. We abstract from other government activities and, therefore, assume that other taxes and expenditures are set equal to zero. The government sets nominal money supply at each moment of time. ${ }^{5}$

Plugging equation (2) into equation (1), maximizing utility $\left.\left(=\int_{0}^{\infty}\left[u\left(c_{t}\right)-l_{t}\right] e^{-\rho t} d t\right]\right)$ with respect to $c$ and $m$ subject to budget constraint (3), and focusing on interior solutions, i.e., $c>0, l>0$, we get:

$$
u^{\prime}\left(c_{t}\right)-1=\lambda,
$$

and

$$
V^{\prime}\left(m_{t}+Z\left(m_{t}^{e}\right)\right)=\lambda i_{t}
$$

where $\lambda$ stands for the Lagrange multiplier, which is constant over time and determined by equality between present discounted value of endowment and consumption. All of these assumptions are standard in monetary models aimed at highlighting fundamental monetary phenomena - in the present case Liquidity Deflation.

To rule out consumption satiation, I will assume $u^{\prime}(y)>1$. Thus, by (4) and (5), we get equilibrium consumption $c=y$, and (dropping time subscripts):

$$
\frac{V \prime\left(m+Z\left(m^{e}\right)\right)}{u \prime(y)-1}=i,
$$

Thus, by equation (6), and recalling that $V^{\prime \prime}<0$, there exists a function $L(i, y)$, such that

$$
m=L(i, y)-Z\left(m^{e}\right), L_{i}<0, L_{y}>0,
$$

${ }^{5}$ As is well known (Olivera 1970, Sargent and Wallace 1975), when prices are perfectly flexible and fiscal constraints are not binding, as in the present model, setting $i$ does not anchor the price level. However, I will extend the model to the case of interest-bearing "money," where the latter could be identified with the policy interest rate, as in Calvo and Végh (1995). 
Equation (7) is a IS/LM familiar expression for equilibrium in the money market, except for the term $Z\left(m^{e}\right)$. Clearly, by (7), recalling that $Z^{\prime}<0$, the demand for money increases with the equilibrium real stock of money, a conventional "network" effect (see, e.g., Uribe 1987). Thus, although the $Z$ function is here associated with a novel form of externality (i.e., liquidity deflation), the effects would be similar if $Z$ is interpreted as a more familiar network externality.

At equilibrium in the money market we have $m=m^{e}$, implying, by (7),

$$
m+Z(m)=L(i, y), L_{i}<0, L_{y}>0 .
$$

Therefore, recalling expression (2), transactions services, i.e., $m+Z(m)$, may increase with real monetary balances despite the Liquidity Deflation effect, but the model does not preclude the possibility that, beyond a certain point, transactions services decline. Condition (8) is depicted in Figure 1, where $m^{*}$ is assumed to maximize $m+Z(m)$ with respect to $m$ (hence $Z^{\prime}\left(m^{*}\right)=-1$ ). The slope of the equilibrium transaction-services equilibrium condition is downward sloping with respect to the nominal interest rate to the left of $m^{*}$, as in conventional models that ignore the $Z$ component. However, the slope becomes positive to the right of $m^{*}$. Notice that $m^{*}$ is associated with $i^{*}$ in Figure 1. Moreover, if $i>i^{*}$, there may be two values of real monetary balances that are consistent with full equilibrium. This is illustrated in Figure 1 by $i=i^{\prime}$, at which point the equilibrium real monetary balances can settle at $m 1$ or $m 2$. Thus, given nominal money supply, the price level may be undetermined. Moreover, I will show in Appendix A that there exists a continuum of equilibrium paths converging to $m 2$, even if the rate of expansion of money supply is constrained to be constant over time. ${ }^{6}$ This shows that Liquidity Deflation can bring about equilibrium indeterminacy, a major complication for the design of monetary policy. Despite this, however, full capacity utilization is still reachable. However, I will show next that full capacity utilization may not be reachable if $i<i^{*}$, due to the existence of a new type of Liquidity Trap.

Consider the case in which the nominal interest rate equals $i^{\prime \prime}<i^{*}$ (see Figure 1). By equation (8) and Figure $1, m^{*}+Z\left(m^{*}\right)<L(i ", y)$. Hence, $i$ " is incompatible with general equilibrium. If full capacity utilization holds, i.e., $c=y$, for instance, the money market would exhibit excess demand, a situation that is not resolved by a fall in the price level or increase in money supply (given $i=i^{\prime \prime}$ ), because Liquidity Deflation prevents the relevant liquidity concept from rising. Thus, if for some reason $i$ is stuck at $i$ ", the economy would display characteristics akin to a Keynesian Liquidity Trap, except that the latter would be generated by liquidity supply

\footnotetext{
${ }^{6}$ The math involved here is very similar to that in the Optimum Seigniorage problem.
} 
phenomena. I will correspondingly call it Supply Side Liquidity Trap, SSLT. ${ }^{7}$ Next I will discuss situations in which it may be difficult for the economy to get rid of SSLT, and even cases in which equilibrium displays some kind of capacity underutilization.

Prior to the Great Recession, a dominant view was that deflation and Liquidity Trap problems could be cured by increasing money supply and raising inflation expectations in a credible manner (see, e.g., Krugman 1998). In the present model this would correspond to being able to raising the nominal interest rate such that $i \geq i^{*}$. True, Liquidity Deflation can still cause equilibrium multiplicity but, as noted, full capacity utilization is not beyond reach. How to get there? By equation (6), in steady state equilibrium we have $i=\rho+\mu$, where $\mu$ is the (constant) rate of expansion of money supply. Hence, all it takes to move the economy out of SSLT is to set $\mu$ such that $\rho+\mu \geq i^{*}$. In words, all it takes is high enough inflation expectations, which may be achieved by jacking up the rate of expansion of money supply in a credible manner (as proposed in Krugman 1998). Unfortunately, as I argue next, Liquidity Deflation could make the Krugman proposal hard to accomplish.

To simplify the discussion, consider the case in which $m+L(m)=m^{*}+Z\left(m^{*}\right)$, for all $m \geq m^{*} .8$ This situation is depicted in Figure 2, where the solid curve is now flat for all $m \geq m^{*}$, and $m 2$-type equilibrium on Figure 1 is ruled out (see graphical proof in Appendix B). Notice that the solid curve looks like the typical textbook Keynesian Liquidity Trap, which, after a critical point ( $m^{*}$ in the present case), becomes infinitely elastic with respect to the interest rate. Suppose that the increase in $\mu$ fails to change inflation expectations. Hence, given rationality, at steady state the representative individual should expect inflation to be constant over time, and such that $\pi=i^{\prime \prime}-\rho$. Thus, if $\mu>i^{\prime \prime}-\rho$, then $m$ will increase without bound, but it would fail to change the relevant liquidity concept (which will remain constant at $m^{*}+Z\left(m^{*}\right)$ ). Excess demand for money would continue to prevail, a situation that may plausibly lead agents to expect that, if anything, inflation will fall, making money more attractive - a situation that would look as if a Liquidity Deflation "black hole" is swallowing the entire expansion of money supply!

I will show next that by modifying the equilibrium concept in a simple but not implausible manner, the model could exhibit capacity underutilization or inefficient allocation of resources, without violating transversality conditions and, thus, qualifying as a rational expectations equilibrium. I will assume that under SSLT and excess money demand, individuals divert their attention to finding/developing alternative liquid assets (e.g., crypto-currencies, searching for yield, etc.) in detriment of their endowments, $y$. Moreover, these negative effects on output do not stop until effective endowment shrinks and restores equilibrium in the money

${ }^{7}$ See Figure 1, where the set of non-negative interest rates associated with SSLT are indicated.

${ }^{8}$ This holds if $Z^{\prime}(m)=-1$, for all $m \geq m^{*}$. 
market. ${ }^{9}$ Thus, if the economy is stuck at $i=i^{\prime \prime}$, the equilibrium effective endowment, denoted by $y^{\prime}$, must satisfy:

$$
m+Z(m)=L\left(i^{\prime \prime}, y^{\prime}\right)
$$

Clearly, $y^{\prime}<y$ and $m \leq m^{*}$. The higher is $m$, the higher will be $y^{\prime}$. Consider the case, depicted in Figure 2, in which $m=m^{*}$ and, therefore, $y^{\prime}$ attains its maximum value subject to $i=i^{\prime \prime}$ ( but still $y^{\prime}<y$ ). ${ }^{10}$ This excess capacity equilibrium is not affected by changes in $\mu$. To be sure, if $\mu>\pi, m$ will grow without bound but, as pointed out before, this does not violate transversality conditions because the stock of relevant liquidity will remain constant at $m^{*}+Z\left(m^{*}\right)$. Since output stays constant and $m$ increases without bound, velocity falls over time. ${ }^{11}$ This is in line with what happened during the Great Recession, as the velocity of circulation exhibited a steep decline in reserve-currency economies. Admittedly, the present model is still quite unsophisticated and should greatly benefit from plausible dynamic extensions, but I would be surprised if its central results could be easily overturned. ${ }^{12}$

Remark II. It is worth keeping in mind that if the rate of expansion of money supply, $\mu$, is high enough, there exists a full capacity utilization equilibrium. Thus, recalling Figure 1, it would be correct to say that full capacity utilization could be achieved by credibly manipulating money supply so that (in steady state) $i \geq i^{*}$. However, the discussion also reveals that if, for some reason, the economy is stuck at $i<i^{*}$, it may not be possible to achieve full capacity utilization by large infusions of money supply, if the representative individual expects low inflation and equilibrium $i<i^{*}$. In that situation, there will be excess demand for money combined with excess supply of full capacity utilization output, $y-$ which the model assumes will lead agents to divert their attention to unproductive activities aimed at increasing the supply of liquid assets. This is an interesting implication of the model, because it offers a new rationale for why it might be hard to have agents believe that inflation will be high enough and generate full capacity utilization. Krugman (1998) made important strides in that direction by claiming that the problem in Japan was that, for some reason, the government was perceived by

9 This is akin to demand-determined output assumption in Keynesian models, although supply factors are at work!

10 In the standard IS/LM apparatus the adjustment mechanism is parallel to the one assumed here, but relies on sticky prices and demand-determined output. See Calvo (2018) for an analysis of Liquidity Deflation in terms of a New Keynesian model with those characteristics.

11 It is worth noting that the same type of SSLT equilibrium would hold if the curve in Figure 1 becomes flat at some $m>m^{*}$ or, in other words, if there exists some $m=m^{* *}>m^{*}$, such that the liquidity of $m$, i.e., $m+Z(m)$, becomes constant for all $m>m^{* *}$.

12 For a New Keynesian Macroeconomics model in which Liquidity Deflation brings about a fall in the velocity of circulation, see Calvo (2018). 
agents as being strongly inflation averse, which conspired against credibility and hence effectiveness of an inflationary strategy. The present model offers another reason: if agents' inflation expectations are "too low," the central bank may be unable to jack up inflation because the economy will be stuck at a SSLT where monetary policy is ineffective. It is not the government's inflation aversion that is at stake here, it is the excessively low inflation expectations of the representative individual - expectations that turn out to be rational - giving rise to excess supply of full capacity output and an insatiable demand for liquidity!

However, recalling Figure 1, the model implies that full capacity utilization could be achieved if the government couples monetary policy with regulations and arrangements that ensure that inflation is such that $i=\rho+\pi>i^{*}$ or, equivalently, that $\pi>i^{*}-\rho$. This involves heterodox procedures that many policymakers try, quite understandably, to avoid. But when all the orthodox procedures have failed, price guidance looks increasingly attractive. Besides, controlling just a handful of prices, e.g., those of public sector services and some large private enterprises, may be enough. This has occasionally been tried in economies facing the opposite problem: stopping chronic inflation. ${ }^{13}$

Remark III. SSLT shows the possibility of persistent excess demand for liquidity at full capacity utilization, which in the present model induces unproductive search for alternative forms of liquidity. I suspect that here rests a wealth of new insights that could be found by, on one end, studying empirically plausible endogenous mechanisms of private-sector liquidity creation - and, on the other end, modeling realistic policymakers' response functions in Liquidity Trap crisis episodes. As to the latter, it is not unusual for policymakers to "fight the last war," and take measures (i.e., reaction functions) that are counterproductive in the short run. The Great Recession, for instance, has induced tighter banking and financial regulations that some observers see as having exacerbated liquidity shortage. Moreover, the very existence of rational expectations SSLT equilibrium may lead the central bank to prematurely stop pursuing $\mathrm{QE}$ and debilitating the effectiveness of $\mathrm{QE}$ if resumed. ${ }^{14}$

Remark IV. I guess that Keynes would have been pleased by these results. He spent much of Chapter 19 on his General Theory discussing several instances in which even downward flexible wages would fail to achieve full capacity utilization. Unfortunately, he utilizes arguments that are absent in the previous sections of the book. The lack of microfoundations helps to explain why popular Keynesian models assume price stickiness and ignore the case in which unemployment arises under flexible prices/wages. However, the PTM (recall footnote 3, above) shows that

\footnotetext{
13 See Bruno et al 1991.

14 Recently, the ECB and the BOJ appear to have given up fighting deflation by means aggressive QE and switched instead to low interest rates. Opinion in the financial press was unanimous in concluding that QE had run out of steam, an additional factor militating against the effectiveness of QE.
} 
Keynes was trying to find a microfoundations for the positive value of (fiat) money based on the existence of output collateral that money holders could attach if there is a run on money. The PTM relies on collateral based on price/wage stickiness. But the collateral could be provided by other means, e.g., government commitment to exchange money for public services/goods at a given nominal price, except if their supply hits bottom. This is how the Gold Standard worked under normal circumstances. Once a collateral principle for the value of money is assumed - and the collateral is, realistically, finite - it is a natural corollary that money's liquidity services must have an upper bound. This implies that a phenomenon like Liquidity Deflation must eventually become operative and set an upper bound to the liquidity generated by money. Hence, in line with the above model, a SSLT could take place without private sector price/wage stickiness, the result that I believe Keynes was trying to get.

Remark V. Although, as pointed out in footnote 6, inflation targeting based on the management of a short-run interest rate results in price level indeterminacy, the model could be extended to the case in which the central bank pays interest on $m$, and $m$ is identified with an aggregate of highly liquid assets. Denote the interest rate on $m$ by $i^{m} .15$ It is easy to show that the money-market equilibrium condition (7) would become:

$$
m+Z(m)=L\left(i-i^{m}, y\right), L_{i-i^{m}}<0, L_{y}>0 .
$$

Clearly, lowering $i^{m}$ reduces the demand for liquidity services and pushes the economy towards full capacity utilization. ${ }^{16}$ However, this policy may not be feasible or give rise to problems of its own. For instance, $i^{m}<0$ may lead to devising crypto-currencies without an effective Lender of Last Resort, and eventually generate severe liquidity crises. ${ }^{17}$

The Optimal Quantity of Money: A Digression. Friedman (1969) shows that abstracting from tax distortions, and assuming that the marginal nominal cost of issuing non-interest-bearing money is nil, the optimum quantity of money - i.e., real monetary balances that maximize social welfare - must be such that the opportunity cost of holding money, i.e., the market nominal interest rate, is equal to

\footnotetext{
15 For a related model, see Calvo and Végh (1995). Variable $i^{m}$ could also be interpreted as central bank's interest on bank reserves.

${ }^{16}$ Changes in $i^{m}$ have effects on the government's consolidated (including the central) fiscal balance and may have an impact on the Liquidity Deflation function, $Z(\bullet)$. However, can be ignored here given that government's deficits/surpluses are financed with lump-sum taxes/subsidies.

17 It is worth noting that a negative $i^{m}$ is equivalent to an inflation tax, which has stimulated Currency Substitution, particularly in economies suffering from Chronic Inflation.
} 
zero, i.e., $i=0$ in the above notation. I will show that this does not necessarily holds under Liquidity Deflation (or network externality).

I will focus on steady state. By equations (1) and (2), the social planner maximizes:

$$
u(c)-c+V(m+Z(m))
$$

with respect to $c \leq y$, and $m \geq 0$. Since $u^{\prime}(y)>1$, optimal consumption $c=y$. The first-order condition with respect to $m$ satisfies:

$$
\left.V^{\prime}(m+Z(m))\left[1+Z^{\prime}(m)\right]\right]=0 .
$$

In absence of Liquidity Deflation, the OQM requires money satiation, i.e., $V^{\prime}=0$, which holds, recalling equation (6), if $i=0$. This is Friedman's result. ${ }^{18}$ Notice that since at steady state $i=\rho+\pi$, in this static model the OQM calls for deflation. More precisely, $\pi=-\rho$.

Consider now the case in which Liquidity Deflation holds. Thus, since by expression (2), $V^{\prime}>0$ everywhere, it follows that the OQM calls for setting $1+Z^{\prime}(m)=0$, which, recalling Figure 1, holds at $m=m^{*}$. Thus, by equation (6), decentralizing the OQM calls for setting the nominal interest rate such that (recalling Figure 1) $i=i^{*}$, where

$$
\frac{V \prime\left(m^{*}+Z\left(m^{*}\right)\right)}{u \prime(y)-1}=i^{*}=\rho+\pi>0 .
$$

Hence, if $i^{*} \geq \rho$, the OQM would call for inflation, not deflation as in Friedman's OQM. Moreover, if money yields a rate of return $i^{m}$, equation (13) becomes:

$$
\frac{V \prime\left(m^{*}+Z\left(m^{*}\right)\right)}{u \prime(y)-1}=i^{*}=i-i^{m}=\rho+\pi-i^{m},
$$

implying that the OQM is achieved if

$$
\pi=i^{*}-\rho+i^{m} .
$$

Thus, the inflation rate is free to take any value as long as it satisfies equation (15).

However, as pointed out above, starting from a SSLT may make it hard for the central bank to implement the OQM. Besides, the OQM $m=m^{*}$ seats at the borderline to the SSLT region (see Fig. 1), too close for comfort! In more general terms this result suggests that policies that generate abundant liquidity services could

\footnotetext{
${ }^{18}$ It is worth noting that Friedman's result is not well defined if there is no liquidity
} satiation, as assumed in equation (2). 
get the economy at the brink of Liquidity Trap, where the benefits of large liquidity may be offset by output loss and inefficiency.

Remark VI. Thus far, our discussion has focused on the limit case in which Liquidity Deflation completely emasculates the impact of QE (Quantitative Easing). However, Liquidity Deflation problems may still be relevant near the limit, where QE is still capable of increasing liquidity supply. For the sake of concreteness, let us go back to the case of non-interest-bearing $m$ and rewrite equation (7) as

$$
m+\beta Z(m)=L(i, y), \beta \geq 0,
$$

and consider the effect of a slight drop in parameter $\beta$. If $Z(m)<0$, i.e., Liquidity Deflation is at work, a smaller $\beta$ amounts to lowering the drag implied by Liquidity Deflation and, therefore, can be interpreted as a shift towards "normality." Since, by assumption, QE still works but it is "small" implies that the derivative of $m+\beta Z(m)$ with respect to $m$ is positive but $\approx 0$. Hence, recalling that $Z(m)<0$, one can easily show that a fall in parameter $\beta$ implies a "large" contraction in equilibrium real monetary balances $m$. Thus, given nominal money, a fall in parameter $\beta$ would result in a "large" increase in the price level. This gives some analytical grounds for the concerns expressed by market analysts that are afraid that regularization of present conditions in which policies like QE seem to be getting out of steam may bring about spike in the price level/inflation. 


\section{CLOSING REMARKS}

Having reached this point, the reader may feel that, if one is ready to assume Liquidity Deflation, the above results are trivial (in the pejorative sense of the word). I beg to disagree. Results are indeed trivial — as it happens with any logically consistent theory - but important. Firstly, because Liquidity Deflation unveils a new type of Liquidity Trap (SSLT) from which it is much harder to escape compared to the textbook case, and helps to rationalize some of the key problems faced by policymakers in the recovery from the Great Recession. Secondly, because it brings up to the surface results that clash with the pre-crisis conventional wisdom. For instance, if you ask your "representative" economist (especially prior the Great Recession): "What happens if money supply displays a large increase in a short period of time?" the answer will likely be something like "prices will take a big jump." In symbols, a big increase in $M$ will result in a big increase in $P$. In contrast, the above discussion focuses on the possibility that a big increase in $M$ will provoke a big fall in the "quality" of $M$ - here identified as a big fall in the "liquidity of $M . "$ Thus, in a situation like that, a marginal increase in $M$ may have no effect on $P$ or in the "real value of $M / P$, adjusted for liquidity services." Thirdly, because Liquidity Deflation - a simple addendum to standard models - might help to develop a "New Synthesis" from which more realistic and complex models will grow (see Calvo 2018). In turn, the opposite strategy, i.e., developing models with a variety of idiosyncratic shocks and assumptions, may actually leave macro theory in limbo, unable to reach professional consensus, and thus making it of little use for policymaking.

The SSLT phenomenon is especially relevant for reserve currencies in economies that have undergone a severe bout of Liquidity Crunch. Until 2008, this was not the case for EMs because Liquidity Crunch of EM assets, drove agents away from domestically denominated assets - a kind of Anti-Liquidity Trap - causing a sharp spike in exchange rates and triggering high inflation (see Calvo $2016 \mathrm{~b}$ ). The reason for this is that a deterioration of EM assets' liquidity did not have a negative impact on the liquidity of global safe assets. This caused portfolio shifts against EM assets. However, this situation started to change with the Lehman crisis and ensuing long period of low interest rates in Advanced Market economies, AMs. A 'search for yield' followed, increasing capital flows towards EM assets, conceivably increasing their liquidity and transforming them into closer substitutes for AM safe assets. As a result, monetary conditions in some EMs started to look like those in AMs. Israel is an interesting case in point. In the 1980s Israel was struggling to get rid of chronic inflation, occasionally reaching staggering levels (e.g., over 350 percent in 1985). At present, however, Israel is facing the opposite problem: deflation! Inflation is below the central banks' inflation target by a wide margin, and is perilously teetering around zero. This could, of course, be due to prudent fiscal and monetary policy. But even so, the external conditions may have contributed to increasing the liquidity of Israel liabilities, putting downward pressure on inflation rates, possibly pushing the economy into a SSLT. 
In closing, it is worth reiterating that the SSLT phenomenon is associated with situations in which it is hard for policymakers to increase the stock of liquid assets to levels compatible with full capacity utilization. The phenomenon is likely to lose its relevance as economies recover and find new Safe Assets. Once 'normality' is recovered, the old ghost of inflation is likely to revive, and take our attention away from Liquidity Trap, as it was the case after the 1930s. This could be a serious mistake if the genie is out of the bottle and the financial sector continues generating new forms of global liquid assets, not protected by a Lender of Last Resort. 
Figure 1. Liquidity Market (Dis) Equilibrium

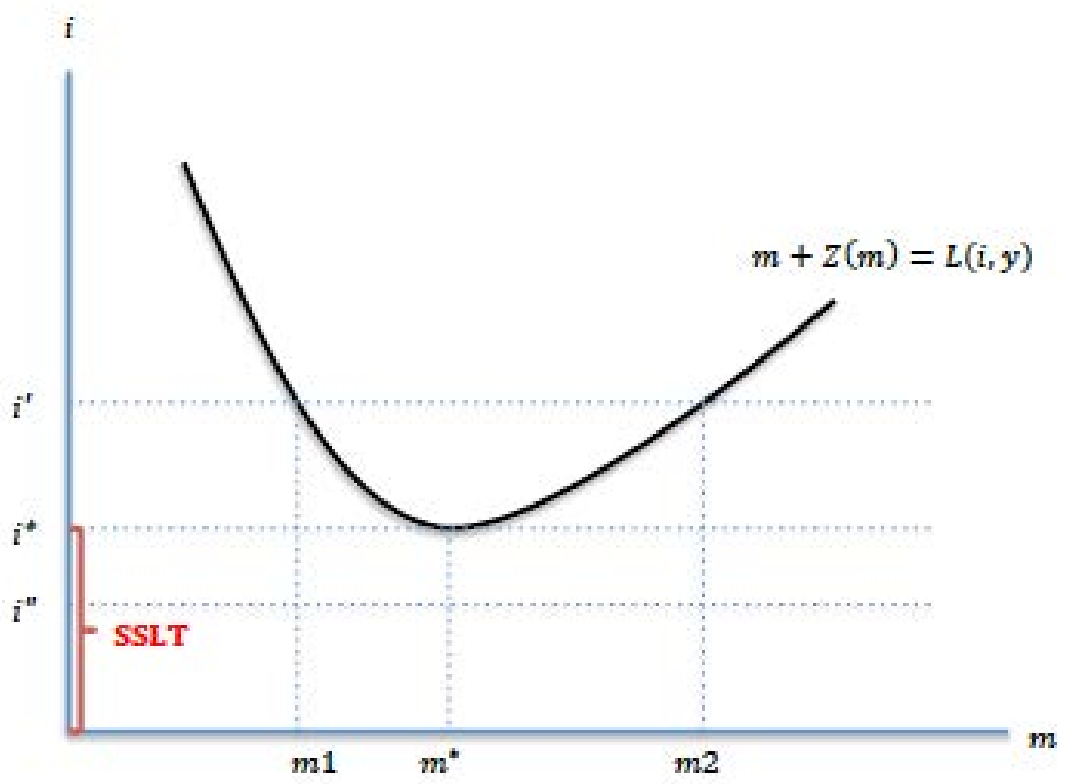

Figure 2. Supply-Side-Liquidity-Trap Equilibrium

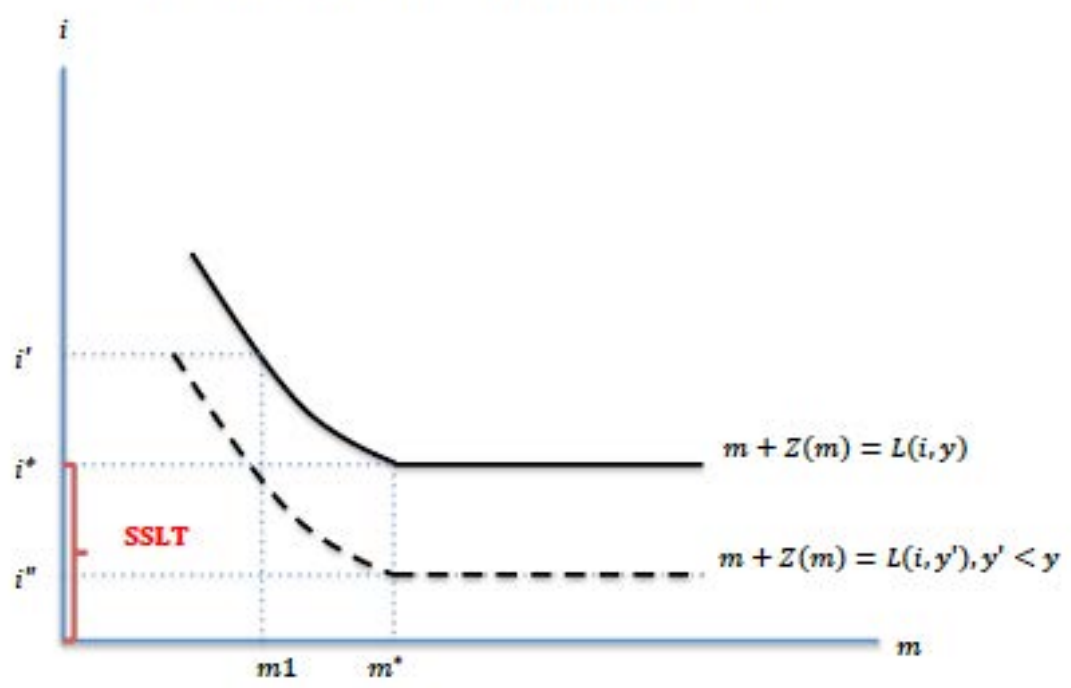




\section{Appendix A}

The analysis in the body of the paper focused on steady-state equilibria. I will sketch out an extension to the general case, but ruling out explosive equilibrium solutions, a conventional assumption in rational expectations models. Moreover, I will constrain the attention to non-interest-bearing money.

Dropping time subscripts, and recalling that nominal money stock is assumed to grow at a constant rate $\mu$, we have

$$
\frac{\dot{m}}{m}=\mu-\pi \text {. }
$$

Moreover, since this is an economy subject to perfect capital mobility, no trade barriers, and that international relative price between importables and exportables is constant over time, it follows that the nominal interest rate satisfies Fisher's equation, i.e.,

$$
i=\rho+\pi
$$

Hence, by equations (6) and (A2), at equilibrium we have

$$
-\pi=\rho-\frac{V^{\prime}\left(m+Z\left(m^{e}\right)\right)}{u^{\prime}(y)-1}
$$

This is a representative-individual economy in which, at equilibrium, $m=m^{e}$. Thus, plugging (A3) in equation (A1), we have

$$
\frac{\dot{m}}{m}=\mu+\rho-\frac{V^{\prime}(m+Z(m))}{u \prime(y)-1}
$$

Therefore, at steady state (where $\dot{m}=0$ ), we have

$$
\frac{d \dot{m}}{d m}=-\frac{V^{\prime \prime}(m+Z(m))\left[1+Z^{\prime}(m)\right]}{u \prime(y)-1} .
$$

Let us examine the steady states $m 1$ and $m 2$ in Figure 1 . Since the curve is downward sloping at $m 1$, it follows that $V^{\prime \prime}(m+Z(m))\left[1+Z^{\prime}(m)\right]<0$. Therefore, $d \dot{m} / d m>0$, and $m 1$ is locally unstable. But the same procedure leads to the conclusion that $m 2$ is stable and gives rise to a continuum of equilibrium paths converging to $\mathrm{m} 2$. Liquidity Deflation is behind this indeterminacy, even though these equilibrium paths do not display Liquidity Trap. This is interesting because as in Remark VI the presence of Liquidity Deflation can generate macroeconomic irregularities, even out of the area where full capacity can hold.

Notice that uniqueness of equilibrium would hold, if, for instance, $i>i^{*}$, and $V(m+Z(m))=V\left(m^{*}+Z\left(m^{*}\right)\right)$, for all $m \geq m^{*}$, as assumed in Figure 2 . 


\section{Appendix B}

Figure B1. Graphical Derivation of Figure 2

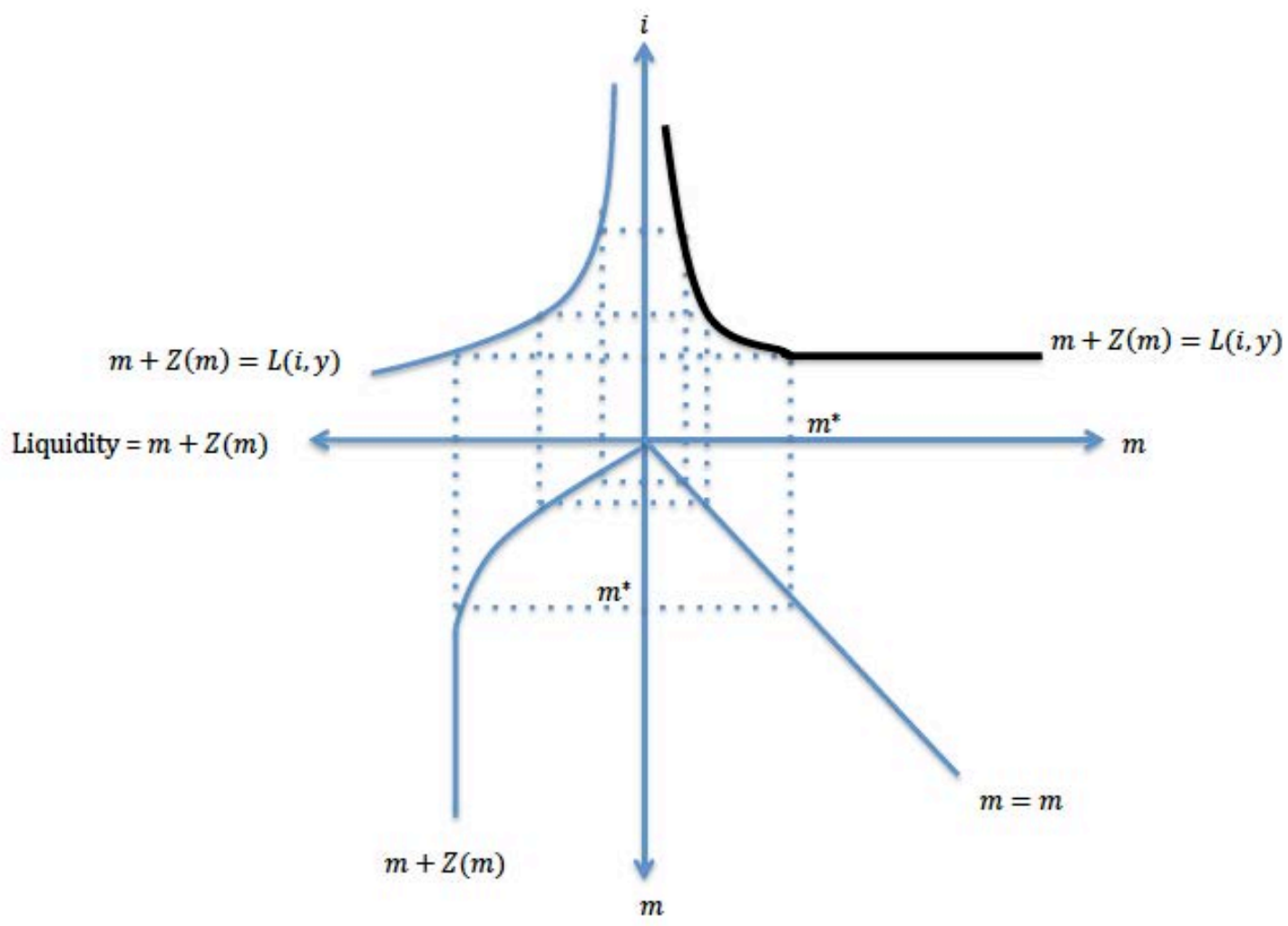




\section{REFERENCES}

Bruno, Michael, Stanley Fischer, Elhanan Helpman, and Nissan Liviatan, with Leora (Rubin) Meridor, 1991. Lessons of Economic Stabilization and Its Aftermath;

Cambridge, MA: MIT Press.

Caballero, Ricardo J., and Emmanuel Farhi, 2014. "The Safety Trap," NBER WP 19927.

Caballero, Ricardo J., Emmanuel Farhi, and Pierre-Olivier Gourinchas, 2016. "Safe Asset Scarcity and Aggregate Demand," American Economic Review, May, pp. 513518

Caballero, Ricardo J., Emmanuel Farhi, and Pierre-Olivier Gourinchas, 2017. "The Safe Assets Shortage Conundrum," Journal of Economic Perspectives, Summer, Vol. 31, No. 3, pp. 29-46.

Calvo, Guillermo A., 2012. "The Price Theory of Money, Prospero's Liquidity Trap, and Sudden Stop: Back to Basics and Back," NBER Working Paper 18285.

Calvo, Guillermo A., 2016 a. "From Chronic Inflation to Chronic Deflation: Focusing on Expectations and Liquidity Disarray Since WWII," NBER WP 22535.

Calvo, Guillermo A., 2016 b. Macroeconomics in Times of Liquidity Crises: Searching for Economic Essentials; Cambridge, MA: MIT Press.

Calvo, Guillermo A., 2018. "Liquidity Deflation: Supply-Side Liquidity Trap, Deflation Bias and Flat Phillips Curve," September 24, in www.columbia.edu/ gc2286.

Calvo, Guillermo A., and Carlos A. Végh, 1995. "Fighting Inflation with High Interest Rates: The Small-Open Economy under Flexible Prices," Journal of Money, Credit, and Banking 27, pp. 49-66.

Fisher, Irving, 1933. "The Debt-Deflation Theory of Great Depressions," Econometrica 1 (4), pp. 337-357.

Friedman, Milton, 1969. The Optimum Quantity of Money, and Other Essays, Chicago, IL: Aldine Publishing Company.

Gorton, Gary, 2010. Slapped by the Invisible Hand: The Panic of 2007; Oxford University Press. 
Ha, Jongrim, M. Ayhan Kose, and Franziska Ohnsorge, 2019. Inflation in Emerging and Developing Economies, The World Bank.

Krugman, Paul R., 1998. "It's Baaack: Japan's Slump and the Return of the Liquidity Trap," Brookings Papers on Economic Activity, 2, pp. 137-187.

Olivera, Julio H.G., 1970. "On Passive Money," Journal of Political Economy, Vol. 78, 4, Part 2: Key Problems of Economic Policy in Latin America, pp. 805-814.

Sargent, Thomas J., and Neil Wallace, 1975. "Rational Expectations, the Optimal Monetary Policy Instrument, and the Optimal Money Supply Rule," Journal of Political Economy, 83, April, pp. 241-254.

Uribe, Martín, 1997. "Hysteresis in a Simple Model of Currency Substitution," Journal of Monetary Economics 40, pp. 185-202.

Végh, Carlos A., 1989. Government Spending and Inflationary Finance: A Public Finance Approach, Staff Papers, International Monetary Fund, Vol. 36, No. 3, pp. 657677. 